\title{
Nanofluids as Heat Transfer Fluids for High-efficiency Caloric Heat Pumps
}

\author{
Adriana Greco ${ }^{2}$, Ciro Aprea ${ }^{1}$, Angelo Maiorino $^{1}$, Claudia Masselli $^{1 *}$ \\ ${ }^{1}$ DIIn, University of Salerno, Via Giovanni Paolo II, 132 Fisciano (SA) 84084, Italy \\ ${ }^{2}$ DII, University of Naples “Federico II”, P.le Tecchio 80, Napoli 80125, Italy
}

Corresponding Author Email: cmasselli@unisa.it

https://doi.org/10.18280/ti-ijes.632-419

Received: 18 February 2019

Accepted: 26 April 2019

\section{Keywords:}

caloric, cooling, heat-pumping, nanofluid

\begin{abstract}
Solid-state is the new frontier of Not-In-Kind technologies arisen as possible future replacement of vapor-compression-based systems. Caloric cooling and heat-pumping found their operation on caloric effect; a class of thermo-physical effects detected in caloric materials following an adiabatic change of the intensity of an applied external field, that results in a variation of the temperature in the material itself. A Brayton-based thermodynamical cycle, called Active Caloric Regenerative cycle, is used to build caloric cooling systems or heat-pumps. In ACR cycle the caloric material acts both as refrigerant and as regenerator and an auxiliary Heat-Transfer Fluid (HTF) is employed to vehiculate heat fluxes between the cold and hot environments. The most common HTF is water but advanced solutions could be adopted to enhance the heat exchange coefficients, like nanofluids. Nanofluids are suspensions consisting of solid high-thermal-conductivity nanoparticles dispersed in a base fluid to enhance the global thermal conductivity of the fluid.

In this paper we investigate, numerically, the energy performances of a caloric heat pump employing water-based $\mathrm{Al}_{2} \mathrm{O}_{3}$ nanofluids as $\mathrm{HTF}$. The analysis is perpetuated changing both the nanofluid volume concentrations and the caloric materials employing electrocaloric, elastocaloric and barocaloric ones.
\end{abstract}

\section{INTRODUCTION}

Solid-state caloric heat-pumping is the new frontier of NotIn-Kind (NIK) technologies arisen as possible future replacement of vapor-compression-based systems [1-3]. This technology has the strong point to not employ greenhouse gases, that can result toxic or damaging for the environment and that can contribute to increase global warming, together with presenting improvements in energy efficiency and exhibiting the potential of recycling its components [4-7].

Caloric effect, an intrinsic property of caloric materials, is the physical phenomenon which solid-state heat-pumping is based on: a temperature variation in the material is detected if an applied external field changes its intensity, adiabatically. Measures of caloric effect are:

$\Delta s=\int_{Y_{0}}^{Y_{1}}\left(\frac{\partial X}{\partial T}\right)_{Y} d Y$

$\Delta T_{a d}=-\int_{Y_{0}}^{Y_{1}} \frac{T}{C}\left(\frac{\partial X}{\partial T}\right)_{Y} d Y$

The nature of the driving field Y particularizes the caloric effect. Magnetic fields applied to a magnetocaloric materials give rise to magnetocaloric effect (MCE) where $\mathrm{Y}=\mathrm{H}$ and $\mathrm{X}=\mathrm{M}$, electric fields to electrocaloric effect (ECE) [8] where $\mathrm{Y}=\mathrm{E}$ and $\mathrm{X}=\mathrm{P}$, mechanical stress to elastocaloric effect $(\mathrm{eCE})$ [9], where $Y=\sigma$ and $X=\varepsilon$, pressure field to barocaloric effect (BCE) [10] where $Y=-p$ and $X=V$.

Caloric effects are applied in a Brayton-based thermodynamical cycle experienced by an Active Caloric Regenerator (ACR), made of the caloric refrigerant which acts both as refrigerant and regenerator to recover heat fluxes. ACR counts four processes, executed sequentially and cyclically, experimented by the regenerator to which the external field is applied and crossed by a thermo-vector fluid. The latter connect thermally a cold and a hot reservoir (CHEX and HHEX). The four processes are:

(1) Adiabatic field decreasing, with consequent reduction of the caloric-material temperature;

(2) Fluid flows from hot to cold side, cooling itself and then reaching the cold heat exchanger, where it absorbs heat from the latter, producing a cooling load.

(3) Adiabatic field increasing, during which the intensity of the external field is increased causing the increasing of the material temperature, due to caloric effect;

(4) Fluid flows from cold to hot side, cooling the regenerator and rejecting heat in the HHEX, thus producing a heating load. This process realizes the desired effect for heatpumping operation mode.

As seen from the above described ACR cycle, the auxiliary heat transfer fluid plays a key-role since it is responsible of transferring heat fluxes and therefore the more efficient is the solid-to-fluid heat exchange, greater are the energy performances of the caloric heat-pump. The most common HTF employed in Active Caloric Regenerator is water but advanced solutions could be adopted to enhance the heat exchange coefficients [11]. Among them, an innovative HTF could be represented by nanofluids [12]. Nanofluids are suspensions consisting of solid high-thermal-conductivity 
nanoparticles (1-100 nm) dispersed in a base fluid to enhance the thermal conductivity of the resulting fluid. The conception of nanofluid, formulated by dispersing metallic or nonmetallic nanometer-size particles in base liquids such as water and ethylene glycol, was proposed first by Choi [13] in 1995 and, a few years later, Choi et al. [14] showed that the addition of a small amount (less than $1 \%$ by volume) of nanoparticles to conventional heat transfer liquids increased the thermal conductivity of the fluid up to approximately two times. Ever since, there have been great research-interests in exploring the effectiveness and feasibility of using nanofluids as convective heat transfer fluids. As a matter of fact, nanofluids are potential heat transfer fluids with enhanced thermophysical properties and heat transfer performance. They can be applied in many devices for better performances (i.e. energy, heat transfer and other performances), so the number of potential applications of this technology is extremely vast. Specific application of nanofluids in engine cooling, solar water heating, cooling of electronics, cooling of transformer oil, improving diesel generator efficiency, cooling of heat exchanging devices, improving heat transfer efficiency of chillers, domestic refrigerator-freezers, cooling in machining, in nuclear reactor and defense and space have been studied and investigated by nanofluids-scientific community [15]. Among them, extremely exiguous is the number of investigations on nanofluids as auxiliary heat-transfer fluid of caloric cooling and heat-pumping devices: literature accounts only two works conducted in Active Magnetocaloric Refrigerators field. Chiba in his work [16] tested the energy performance of an Active Magnetocaloric Regenerative refrigeration (AMR) cycle operating near room temperature using nanofluids as heattransfer fluid, in order to enhance the heat transfer in the regenerator bed during the fluid-flow phases. Mugica et al. [17], analyzed the energetic and exergy performances of parallel-plate AMR refrigerator though a 1-D model. Both of the investigations $[16,17]$ employed water-based $\mathrm{Al}_{2} \mathrm{O}_{3}$ nanofluids as HTF. Therefore, literature did not account of investigations conducted on caloric effect different from magnetocaloric one. This paper aims to fulfill this gap, presenting the results of a numerical investigation on the energy performances of a caloric heat pump employing waterbased $\mathrm{Al}_{2} \mathrm{O}_{3}$ nanofluids as $\mathrm{HTF}$ while the regenerator works with electrocaloric, elastocaloric and barocaloric materials. The tests were performed through a 2-Dimensional model solved with Finite Element Method and the analysis is perpetuated changing both the nanofluid volume concentration and the caloric materials.

\section{MODELLING ACR HEAT PUMP, MATERIALS, NANOFLUIDS}

This section describes all the aspects regarding the physics and the structure- modelling: Active Caloric Heat Pump modelling, the physics and the modelling of: the caloric-effect materials as refrigerants; the nanofluids as heat transfer fluids.

\subsection{Modelling active caloric regenerative heat pumps}

The behavior of a caloric heat pump is described through a 2-D model, already introduced [18, 19] and validated [20-22] in previous investigations. The geometry of the heat pump sees a parallel-plate regenerator made of caloric material, separated by channels in which the Heat Transfer Fluid (HTF) crosses the regenerator. The desired effect is to add heat to the indoor room connected with a hot heat exchanger at $\mathrm{T}_{\mathrm{H}}$. The cold heat exchanger is coupled with the outdoor environment, whose temperature is $\mathrm{T}_{\mathrm{C}}$. Below there is the mathematical structure that the 2-D model is based on:

$$
\begin{aligned}
& \left\{\begin{array}{c}
\frac{\partial u}{\partial x}+\frac{\partial v}{\partial y}=0 \\
\frac{\partial u}{\partial t}+u \frac{\partial u}{\partial x}+v \frac{\partial u}{\partial y}=-\frac{1}{\rho_{n f}} \frac{\partial p}{\partial x}+v\left(\frac{\partial^{2} u}{\partial x^{2}}+\frac{\partial^{2} u}{\partial y^{2}}\right) \\
\frac{\partial v}{\partial t}+u \frac{\partial v}{\partial x}+v \frac{\partial v}{\partial y}=-\frac{1}{\rho_{n f}} \frac{\partial p}{\partial y}+v\left(\frac{\partial^{2} v}{\partial x^{2}}+\frac{\partial^{2} v}{\partial y^{2}}\right) \\
\frac{\partial T_{n f}}{\partial t}+u \frac{\partial T_{n f}}{\partial x}+v \frac{\partial T_{n f}}{\partial y}=\frac{k_{f}}{\rho_{n f} C_{n f}}\left(\frac{\partial^{2} T_{n f}}{\partial x^{2}}+\frac{\partial^{2} T_{n f}}{\partial y^{2}}\right) \\
\frac{\partial T_{s}}{\partial t}=\frac{k_{s}}{\rho_{s} C_{s}}\left(\frac{\partial^{2} T_{s}}{\partial x^{2}}+\frac{\partial^{2} T_{s}}{\partial y^{2}}\right)
\end{array}\right. \\
& \left\{\begin{array}{c}
\rho_{n f} C_{n f} \frac{\partial T_{n f}}{\partial t}=k_{n f}\left(\frac{\partial^{2} T_{n f}}{\partial x^{2}}+\frac{\partial^{2} T_{n f}}{\partial y^{2}}\right) \\
\rho_{s} C_{s} \frac{\partial T_{s}}{\partial t}=k_{s}\left(\frac{\partial^{2} T_{s}}{\partial x^{2}}+\frac{\partial^{2} T_{s}}{\partial y^{2}}\right)+Q
\end{array}\right. \\
& Q=Q\left(\text { field }, T_{S}\right)=\frac{\rho_{S} C_{S}\left(\text { field }, T_{S}\right) \Delta T_{a d}\left(\text { field }, T_{S}\right)}{\tau}
\end{aligned}
$$

Eq. (3) models the fluid-flow processes of the ACR cycle; Eq. (4) describes the field rising/falling phases. Caloric effect is modeled through the Q-term reported in Eq. (5). It converts the caloric effect into a power density. Since Q is a function of the field and the temperature, its mathematical expression has been obtained by a mathematical finder software, as a result of elaboration and manipulation of experimental data of $\mathrm{C}_{\mathrm{s}}$ (field, $\mathrm{T}_{\mathrm{s}}$ ) and $\Delta \mathrm{T}_{\mathrm{ad}}$ (field, $\mathrm{T}_{\mathrm{s}}$ ), coming from scientific literature. Different Q-terms correspond to the tested caloric materials.

The model is solved with Finite Element Method and the ACR cycle runs cyclically several times until reaching steadystate conditions.

\subsection{The selected caloric materials}

To select the caloric refrigerants for the present investigation we based on high-caloric effects and diversity criteria, in order to test the most performing ones, in room temperature range, among the electrocaloric, elastocaloric and barocaloric effect materials.

$\mathrm{Pb}_{0.97} \mathrm{La}_{0.02}\left(\mathrm{Zr}_{0.75} \mathrm{Sn}_{0.18} \mathrm{Ti}_{0.07}\right) \mathrm{O}_{3}$ (PLZST) [23], deposited on $\mathrm{LaNiO} 3 / \mathrm{Si}$ (100) substrate, is the electrocaloric material under test. It exhibits a maximum Giant ECE at $278 \mathrm{~K}$ but $\Delta \mathrm{T}_{\mathrm{ad}}$ remains very high in the range $278 \div 298 \mathrm{~K}$, making PLZST definitely suitable for heat pump applications. Specifically, we considered it under electric field changes of $90 \mathrm{MVm}^{-1}$ and 70 $\mathrm{MV} \mathrm{m}{ }^{-1}$ whose $\Delta \mathrm{T}_{\text {ad }}$ peaks are $54 \mathrm{~K}$ and $43 \mathrm{~K}$, respectively.

We also considered the elastocaloric Ni-Ti polycrystals [24], benchmark of elastocaloric systems, showing a peak at $350 \mathrm{~K}$ but anyway exhibiting a remarkable elastocaloric effect in temperature range devoted to heat pump applications. The considered stress field change is $0.9 \mathrm{GPa}$ which results in a peak of $25 \mathrm{~K}$ as adiabatic temperature change due to elastocaloric effect.

The barocaloric oxyfluorides $\left(\mathrm{NH}_{4}\right)_{2} \mathrm{MoO}_{2} \mathrm{~F}_{4}$ [25] showing a maximum direct barocaloric effect at $272 \mathrm{~K}$ which remains remarkable until $360 \mathrm{~K}$, ensures a good applicability for heat pumps application. The considered drop of applied pressure field is $0.9 \mathrm{GPa}$ that guarantees a maximum of $18 \mathrm{~K}$ due to 
barocaloric effect.

As barocaloric we also focused on Acetoxy Silicon Rubber (ASR) exhibiting a supergiant [26] barocaloric effect investigated for $\Delta p=[0.273 ; 0.390] \mathrm{GPa}$ under which associated maximum $\Delta \mathrm{T}_{\mathrm{ad}}$ of 30 and $41 \mathrm{~K}$ occur, respectively.

\subsection{Modelling nanofluids and their properties}

Basing on the only two previous studies about nanofluids for magnetocaloric applications, we decided to employ the same nanofluid, the alumina-water nanofluid. It is composed of water, as base fluid, in which nanometric particles of alumina $\left(\mathrm{Al}_{2} \mathrm{O}_{3}\right)$ were dispersed. Moreover, to conduct the investigation with nanofluids containing variable volume fraction of alumina, we considered different concentrations of nanoparticles dispersed on equal volume of base fluid as:

$\varphi=\frac{V_{n p}}{V_{n f}}=\frac{m_{n p}}{m_{n f}}$

The thermophysical properties of the alumina-water nanofluids are dependent on the volume fraction of nanofluids $\varphi$; therefore, to include such dependence in our caloric heatpump model, we adopted the following correlations demonstrated in previous investigations $[17,27]$ :

$\begin{aligned} \rho_{n f}= & \frac{m_{n f}}{V_{n f}}=\frac{m_{b f}+m_{n p}}{V_{n f}}=\rho_{b f} \frac{V_{b f}}{V_{n f}}+\rho_{n p} \frac{V_{n p}}{V_{n f}}=(1-\varphi) \rho_{b f}+ \\ & +\varphi \rho_{n p}\end{aligned}$

$C_{n f}=(1-\varphi) C_{b f}++\varphi C_{n p}$

$k_{n f}=k_{b f} \frac{k_{n p}+2 k_{b f}-2 \varphi\left(k_{b f}-k_{n p}\right)}{k_{n p}+2 k_{b f}+\varphi\left(k_{b f}-k_{n p}\right)}$

$\mu_{n f}=(1+7.74 \varphi)$

Table 1 lists the properties of the base fluid and the nanoparticles of alumina-water nanofluids at $\mathrm{T}=293 \mathrm{~K}$ and $\mathrm{p}=1 \mathrm{~atm}$.

Table 1. Thermophysical properties of alumina-water base fluid and nanoparticles

\begin{tabular}{|c|c|c|c|c|}
\hline $\begin{array}{c}\text { Substanc } \\
\text { e }\end{array}$ & {$\left[\begin{array}{c}\rho \\
\frac{k g}{m^{3}}\end{array}\right]$} & $\begin{array}{c}\mathrm{C} \\
{\left[\frac{\mathrm{J}}{\mathrm{kgK}}\right]}\end{array}$ & {$\left[\begin{array}{c}\mathbf{k} \\
\frac{W}{m K}\end{array}\right]$} & {$\left[\begin{array}{c}\mu \\
{\left[\frac{k g}{m s}\right.}\end{array}\right]$} \\
\hline Water & 998.2 & 4182 & 0.597 & $9.93 * 10^{-4}$ \\
\hline $\mathrm{Al}_{2} \mathrm{O}_{3}$ & 3970 & 765 & 36 & - \\
\hline
\end{tabular}

\section{INVESTIGATION AND OPERATIVE CONDITIONS}

The investigation was performed employing the above described set of caloric materials in the 2-D model of the ACR working in the range $278 \div 298 \mathrm{~K}$ in heat-pump operation mode at fixed ACR frequency $(1.25 \mathrm{~Hz})$ and fluid velocity $(0.2 \mathrm{~m} * \mathrm{~s}$ 1). The auxiliary heat-transfer fluid was alumina-water nanofluids with variable concentration $\varphi=[0 ; 0.02 ; 0.04 ; 0.06$ $0.08 ; 0.1]$.

\section{RESULTS}

The results are reported in terms of power of the heat-pump, that measures the power at which the system pumps heat and Coefficient of Performance (COP) defined, respectively, as:

$\dot{Q}_{H}=\frac{1}{\theta} \int_{\tau+n \theta}^{2 \tau+n \theta} \dot{m}_{n f} C_{n f}\left(T_{n f}(L, y, t)-T_{H}\right) d t$

$C O P=\frac{\dot{Q}_{H}}{\dot{W}_{T O T}}$

COP is the coefficient of performance of the heat pump and it is conceived as the ratio between the heating power of the pump and the total energy expense made to get it. $\dot{W}_{T O T}$ embraces both the contribution due to the external field variation and the one connected to the mechanical power required for the fluid motion.

In Figure 1 one can appreciate the heating power of the caloric heat-pump, for the tested materials occurring under the operative conditions of section 3 , when the heat-transfer fluid is alumina-water based nanofluid with variable concentration. General considerations arising through examining the data plotted are that heating power of the heat-pump increases when incrementing nanofluid concentration for all the tested materials, with a medium increment of $19 \%$. PLZST under $\Delta \mathrm{E}=90 \mathrm{MV} \mathrm{m}^{-1}$ as well as Ni-Ti under $\Delta \sigma=0.9 \mathrm{GPa}$ give the highest $\mathrm{Q}_{\mathrm{H}}$ with a maximum of around $580 \mathrm{~W}$ in correspondence of $\varphi=0.1$. This is due to the Giant ECE shown at $278 \mathrm{~K}$ by the former, and to the elastocaloric effect that is quite constant in the operating temperature range. On the contrary the lowest heating-powers are detected for $\left(\mathrm{NH}_{4}\right)_{2} \mathrm{MoO}_{2} \mathrm{~F}_{4}$ since they do not exceed $240 \mathrm{~W}$. Such results are due both to the $\Delta \mathrm{T}_{\mathrm{ad}}$ smaller than PLZST and to the peak located at $272 \mathrm{~K}$ out of the working temperature range.

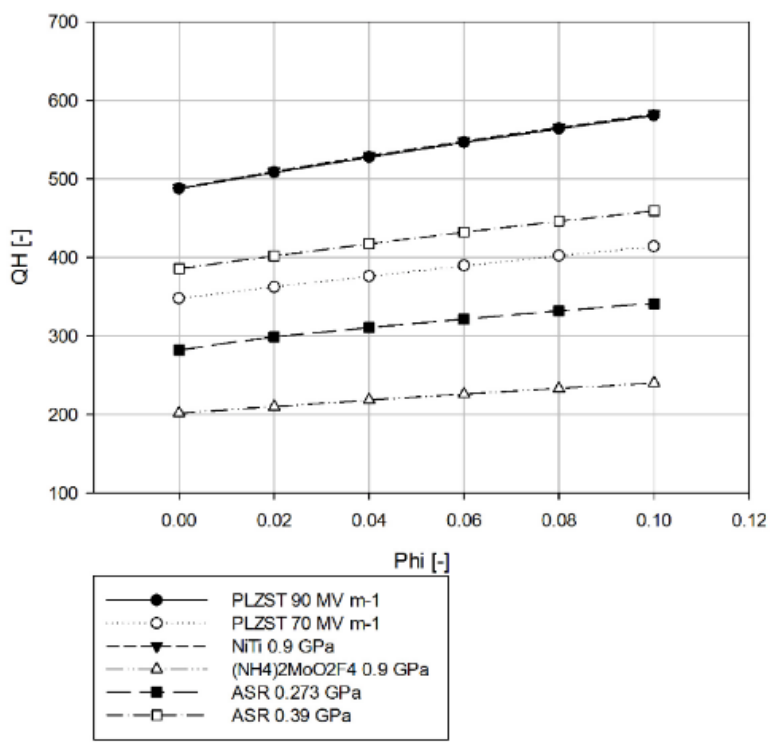

Figure 1. Heating power vs nanofluid concentration for the tested caloric materials

Figure 2 reports the coefficients of performances of the caloric materials under test, evaluated with respect to the variable concentration of the alumina-water based nanofluid. 
The situation is quite different from the data about heatpumping powers, since the highest-COP material is still Ni-Ti but not anymore PLZST that exhibits, for both the 90 and 70

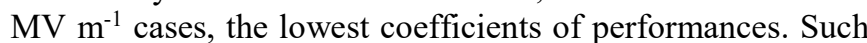
turnarounds are caused by the expenses needed for electricalfield changing, higher than mechanical stretching ones. The $\mathrm{Ni}$-Ti based caloric heat pump presents 14.8 as maximum COP if it works with $10 \%$ alumina- $90 \%$ water nanofluid. A middle COP-increment of $15 \%$ is detected if the nanofluid concentration increases from $0 \%$ up to $10 \%$. The barocaloric Acetoxy Silicone Rubber presents also satisfying COPs with a maximum of 9.3 registered for $\varphi=0.1$ under $\Delta p=0.39 \mathrm{GPa}$ and a middle increment of $19 \%$ while increasing nanofluid concentration.

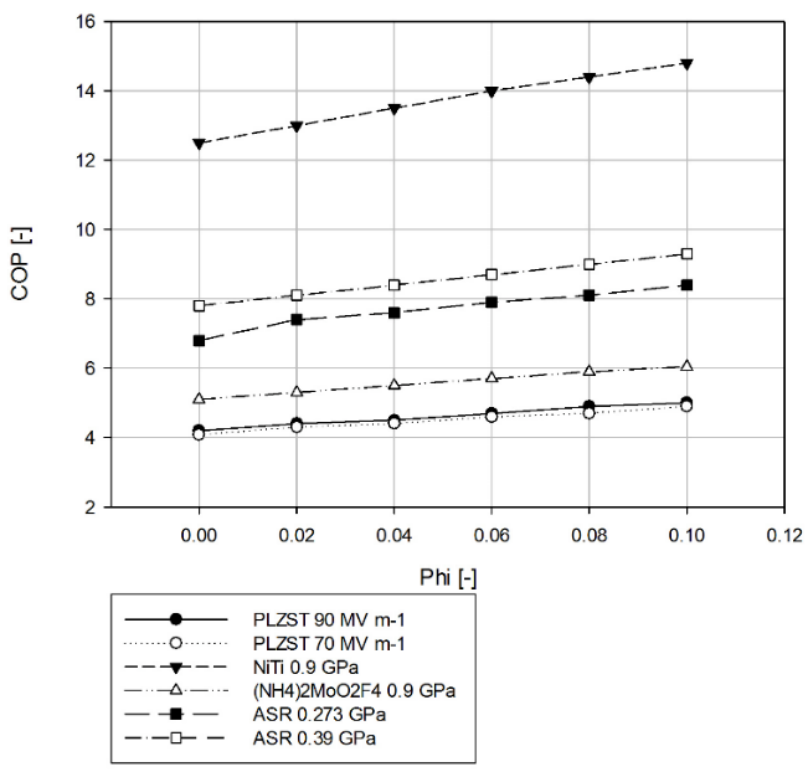

Figure 2. Coefficient of Performance vs nanofluid concentration for the tested caloric materials

\section{CONCLUSIONS}

In this paper we investigated, numerically, the energy performances of a caloric heat pump employing water-based $\mathrm{Al}_{2} \mathrm{O}_{3}$ nanofluids as HTF. The analysis was perpetuated changing both the nanofluid volume concentrations and the materials employing electrocaloric, elastocaloric and barocaloric ones.

The investigation was performed testing a wide set of materials showing remarkable electrocaloric, elastocaloric or barocaloric effects in the temperature range of interest $(278 \div 298 \mathrm{~K})$ for heat pump operation mode. The ACR frequency was fixed $(1.25 \mathrm{~Hz})$ as well as the fluid velocity $(0.2$ m. $\left.\mathrm{s}^{-1}\right)$. The concentration of the auxiliary heat-transfer nanofluid was varied in the range $\varphi=[0 ; 0.02 ; 0.04 ; 0.06 ; 0.08$; $0.1]$.

From the results, reported in terms of power of the heatpump and coefficient of performance, we detected that the effect of working with alumina-water based nanofluids and increasing the concentration, results in an improvement of the energy performances of the caloric heat pump.

General considerations arising through examining the data plotted are that heating power of the heat-pump increases when incrementing nanofluid concentration for all the tested materials, with a medium increment of $19 \%$. The highest ones were measured for PLZST under $\Delta \mathrm{E}=90 \mathrm{MV} \mathrm{m}^{-1}$ and Ni-Ti under $\Delta \sigma=0.9 \mathrm{GPa}$ with a maximum of around $580 \mathrm{~W}$ in correspondence of $\varphi=0.1$. Examining the coefficient of performances, PLZST presents the lowest ones due to the high electrical power needed for electrical-field changing, whereas $\mathrm{Ni}$-Ti presents the highest COPs, too. Anyhow globally, the effect of enhancing nanofluid concentration results in a performance improvement also in terms of COP.

Basing on the results collected, the final considerations that can be drawn are that employing alumina-water nanofluids as auxiliary HTF carries to an upgrading of the energy performances of the caloric heat-pump and that, in this investigation, the best combination of caloric-refrigerant + $\mathrm{HTF}$ is given by $\mathrm{Ni}-\mathrm{Ti}+10 \%$ alumina- $90 \%$ water nanofluid.

\section{REFERENCES}

[1] Aprea C, Greco A, Maiorino A, Masselli C. (2018). Solid-state refrigeration: A comparison of the energy performances of caloric materials operating in an active caloric regenerator. Energy 165: 439-455. https://doi.org/10.1016/j.energy. 2018.09.114

[2] Kitanovski A, Plaznik U, Tomc U, Poredoš A. (2015). Present and future caloric refrigeration and heat-pump technologies. International Journal of Refrigeration 57: 288-298. https://doi.org/10.1016/j.ijrefrig.2015.06.008

[3] Qian S, Nasuta D, Rhoads A, Wang Y, Geng Y, Hwang Y, Radermacher R, Takeuchi I. (2016). Not-in-kind cooling technologies: A quantitative comparison of refrigerants and system performance. International Journal of Refrigeration 62: 177-192. https://doi.org/10.1016/j.ijrefrig.2015.10.019

[4] Aprea C, Greco A, Maiorino A, Masselli C. (2018). The environmental impact of solid-state materials working in an active caloric refrigerator compared to a vapor compression cooler. International Journal of Heat and Technology 36(4): 1155-1162. https://doi.org/10.18280/ijht.360401

[5] Aprea C, Greco A, Maiorino A, Masselli C. (2017). Electrocaloric refrigeration: An innovative, emerging, eco-friendly refrigeration technique. 34rd UIT Heat Transfer $\quad$ Conference 796(1): 012019. https://doi.org/10.1088/1742-6596/796/1/012019

[6] Aprea C, Greco A. (1998). An experimental evaluation of the greenhouse effect in R22 substitution. Energy Conversion and Management 39(9): 877-887. https://doi.org/10.1016/S0196-8904(97)10058-9

[7] Aprea C, Greco A, Maiorino A. (2013). The use of the first and of the second order phase magnetic transition alloys for an AMR refrigerator at room temperature: A numerical analysis of the energy performances. Energy Conversion and Management 70: 40-55. https://doi.org/10.1016/j.enconman.2013.02.006

[8] Aprea C, Greco A, Maiorino A, Masselli C. (2017). A comparison between electrocaloric and magnetocaloric materials for solid state refrigeration. International Journal of Heat and Technology 35(1): 225-234. https://doi.org/10.18280/ijht.350130

[9] Tušek J, Engelbrecht K, Millán-Solsona R, Mañosa L, Vives E, Mikkelsen LP, Pryds N. (2015). The elastocaloric effect: A way to cool efficiently. Advanced Energy Materials 5(13). https://doi.org/10.1002/aenm.201500361 
[10] Strässle T, Furrer A, Dönni A, Komatsubara T. (2002). Barocaloric effect: The use of pressure for magnetic cooling in Ce3Pd20Ge6. Journal of Applied Physics 91(10): 8543-8545. https://doi.org/10.1063/1.1456450

[11] Liu S, Sakr M. (2013). A comprehensive review on passive heat transfer enhancements in pipe exchangers. Renewable and Sustainable Energy Reviews 19: 64-81. https://doi.org/10.1016/j.rser.2012.11.021

[12] Yu W, France DM, Routbort JL, Choi SU. (2008) Review and comparison of nanofluid thermal conductivity and heat transfer enhancements. Heat $\begin{array}{lll}\text { Transfer } & \text { Engineering } & \text { 29(5): }\end{array}$ https://doi.org/10.1080/01457630701850851

[13] Choi SUS, Eastman JA. (1995). Enhancing thermal conductivity of fluids with nanoparticles. Developments and Applications of Non-Newtonian Flows FED 231(66): 99-105.

[14] Choi SUS, Zhang ZG, Yu W, Lockwood FE, Grulke EA. (2001). Anomalously thermal conductivity enhancement in nanotube suspensions. Applied Physics Letters 79: 2252-2254. https://doi.org/10.1063/1.1408272

[15] Saidur R, Leong KY, Mohammad H. (2011). A review on applications and challenges of nanofluids. Renewable and Sustainable Energy Reviews 15(3): 1646-1668. https://doi.org/10.1016/j.rser.2010.11.035

[16] Chiba Y. (2017). Enhancements of thermal performances of an active magnetic refrigeration device based on nanofluids. Mechanics 23(1): 31-38 https://doi.org/10.5755/j01.mech.23.1.13452

[17] Mugica I, Roy S, Poncet S, Bouchard J, Nesreddine H. (2017). Exergy analysis of a parallel-plate active magnetic regenerator with nanofluids. Entropy 19(9): 464. https://doi.org/10.3390/e19090464

[18] Aprea C, Cardillo G, Greco A, Maiorino A, Masselli C. (2015). A comparison between experimental and 2D numerical results of a packed-bed active magnetic regenerator. Applied Thermal Engineering 90: 376-383. https://doi.org/10.1016/j.applthermaleng.2015.07.020

[19] Aprea C, Greco A, Maiorino A, Masselli C. (2015). A comparison between rare earth and transition metals working as magnetic materials in an AMR refrigerator in the room temperature range. Applied Thermal Engineering 91: 767-777. https://doi.org/10.1016/j.applthermaleng.2015.08.083

[20] Aprea C, Cardillo G, Greco A, Maiorino A, Masselli C. (2016). A rotary permanent magnet magnetic refrigerator based on AMR cycle. Applied Thermal Engineering 101: 699-703.

https://doi.org/10.1016/j.applthermaleng.2016.01.097

[21] Aprea C, Greco A, Maiorino A, Masselli C. (2017). Analyzing the energetic performances of AMR regenerator working with different magnetocaloric materials: Investigations and viewpoints. International Journal of Heat and Technology 35: S383-S390. https://doi.org/10.18280/ijht.35Sp0152

[22] Aprea C, Greco A, Maiorino A, Masselli C. (2018). Energy performances and numerical investigation of solid-state magnetocaloric materials used as refrigerant in an active magnetic regenerator. Thermal Science and Engineering Progress 6: 370-379. https://doi.org/10.1016/j.tsep.2018.01.006

[23] Zhao Y, Hao X, Zhang Q. (2015). A giant electrocaloric effect of a Pb 0.97 La 0.02 (Zr 0.75 Sn 0.18 Ti 0.07) O 3 antiferroelectric thick film at room temperature. Journal

of Materials Chemistry C 3(8): 1694-1699. https://doi.org/10.1039/C4TC02381A

[24] Tušek J, Engelbrecht K, Millán-Solsona R, Mañosa L, Vives E, Mikkelsen LP, Pryds N. (2015). The elastocaloric effect: A way to cool efficiently. Advanced Energy Materials 5(13): 1500361. https://doi.org/10.1002/aenm.201500361

[25] Gorev MV, Bogdanov EV, Flerov IN, Kocharova AG, Laptash NM. (2010). Investigation of thermal expansion, phase diagrams, and barocaloric effect in the $\left(\mathrm{NH}_{4}\right)_{2} \mathrm{WO}_{2} \mathrm{~F}_{4}$ and $\left(\mathrm{NH}_{4}\right)_{2} \mathrm{MoO}_{2} \mathrm{~F}_{4}$ oxyfluorides. Physics of the Solid Statep 52(1): 167-175. https://doi.org/10.1134/S106378341

[26] Imamura W, Usuda EO, Paixão LS, Bom NM, Gomes AM, Carvalho AMG. (2017). Supergiant barocaloric effects in acetoxy silicone rubber around room temperature. arXiv:1710.01761.

[27] Bianco V, Vafai K, Manca O, Nardini, S. (2015). Heat transfer enhancement with nanofluids. https://doi.org/10.1201/b18324

\section{NOMENCLATURE}

C

$\mathrm{E}$

$\mathrm{H}$

$\mathrm{k}$

$\mathrm{L}$

M

$\mathrm{m}$

$\mathrm{P}$

$\mathrm{p}$

$\mathrm{Q}$

Q

S

$\mathrm{T}$

$\mathrm{t}$

$\mathrm{u}$

V

$\mathrm{V}$

W

$\mathrm{X}$

$\mathrm{X}$

Y

y

\section{Greek symbols}

$\Delta$

$\varepsilon$

$\theta$

$\mu$

$v$

$\varphi$

$\rho$

$\sigma$

$\tau$

$\begin{array}{ll}\text { Subscripts } & \\ 0 & \text { initial } \\ 1 & \text { final } \\ \text { ad } & \text { adiabatic } \\ \text { bf } & \text { base fluid }\end{array}$

specific heat, $\mathrm{J} \mathrm{kg}^{-1} \cdot \mathrm{K}^{-1}$

electric field, V. $\mathrm{m}^{-1}$

magnetic field, A. $\mathrm{m}^{-1}$

thermal conductivity, W. $\mathrm{m}^{-1}$. $\mathrm{K}^{-1}$

length of the regenerator, $m$

magnetization, A. $\mathrm{m}^{-1}$

mass, $\mathrm{kg}$

polarization $\mathrm{C} . \mathrm{m}^{-2}$

pressure, $\mathrm{Pa}$

power density, W. $\mathrm{m}^{-3}$

power, W

entropy, J. $\mathrm{kg}^{-1} \cdot \mathrm{K}^{-1}$

temperature, $\mathrm{K}$

time, $\mathrm{s}$

longitudinal fluid velocity, $\mathrm{m} . \mathrm{s}^{-1}$

volume, $\mathrm{m}^{3}$

orthogonal fluid velocity, $\mathrm{m}$. $\mathrm{s}^{-1}$

mechanical power, $\mathrm{W}$

conjugate field

longitudinal spatial coordinate, $\mathrm{m}$ applied driving field

orthogonal spatial coordinate, $\mathrm{m}$

finite difference

elongation, \%

period of ACR cycle, $s$

dynamic viscosity, $\mathrm{kg} \cdot \mathrm{m}^{-1} \cdot \mathrm{s}^{-1}$

cinematic viscosity, $\mathrm{m}^{+2} \cdot \mathrm{s}^{-1}$

nanofluid concentration

density, kg. $\mathrm{m}^{-3}$

stress, $\mathrm{Pa}$

period of each step of ACR cycle, $s$ 


\section{C}

$\mathrm{H}$

np cold

hot

nanofluid

nanoparticles constant pressure

solid

total 